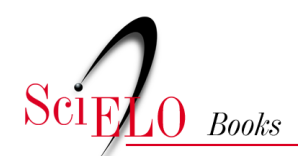

\title{
I - La Ley de Soberanía Alimentaria a los 10 años La soberanía alimentaria en Ecuador a 10 años de la LORSA
}

\author{
Renato Lasso
}

\section{SciELO Books / SciELO Livros / SciELO Libros}

LASSO, R. La soberanía alimentaria en Ecuador a 10 años de la LORSA. In: ESTEBAN, D., ARTACKER, T., and LIZANO, R., coords. Cambio climático, biodiversidad y sistemas agroalimentarios: avances y retos a 10 años de la Ley Orgánica del Régimen de la Soberanía Alimentaria en Ecuador [online]. Quito: Editorial Abya-Yala, 2020, pp. 87104. ISBN: 978-9978-10-466-8. http://doi.org/10.7476/9789978105689.0006.

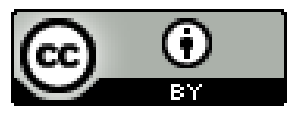

All the contents of this work, except where otherwise noted, is licensed under a Creative Commons Attribution 4.0 International license.

Todo o conteúdo deste trabalho, exceto quando houver ressalva, é publicado sob a licença Creative Commons Atribição 4.0.

Todo el contenido de esta obra, excepto donde se indique lo contrario, está bajo licencia de la licencia Creative Commons Reconocimento 4.0. 


\section{La soberanía alimentaria en Ecuador a 10 años de la LORSA}

Renata Lasso ${ }^{1}$

\section{Antecedentes}

Luego de la Segunda Guerra Mundial se promueve fuertemente la denominada "Revolución Verde" que buscaba un sistema de producción agrícola o ganadero caracterizado por grandes ingresos de capital, alto uso de tecnología y agroquímicos. La producción agrícola a nivel mundial se multiplicó 4 veces entre el año 1820 y 1975 para alimentar a una población mundial que pasó de 1000 millones de personas en el año 1800 a 6500 millones en el año 2002 (Voluntariat Solidari, 2016). Esta agricultura intensiva si bien incrementó los rendimientos, no sólo, no acabó con el hambre en el mundo, sino que, además, ha tenido un elevado costo ambiental que ha provocado destrucción de ecosistemas; pérdida de semillas criollas, es decir de la diversidad alimentaria; infertilidad del suelo; contaminación de fuentes agua; desaparición de insectos útiles, así como, efectos negativos en la salud de las personas por el uso de agroquímicos.

1 Economista agraria, comprometida con la lucha feminista, particularmente con las mujeres rurales, productoras de alimentos, convencida de la necesidad de trabajar en políticas públicas territorializadas para fortalecer la agricultura campesina. 


\section{Seguridad alimentaria y las políticas globales}

En 1974 en el marco de la Conferencia Mundial sobre Alimentación en Roma, cien países adoptan la "Declaración universal para la erradicación del hambre y la malnutrición" y se adopta el concepto de "seguridad alimentaria" con el planteamiento que ante el crecimiento continuo de la población mundial, se tendría que multiplicar la producción de alimentos para asegurar la cantidad necesaria (ONU, 1974). Las estrategias para asegurar la alimentación apuntaron hacia una mayor productividad, sin embargo, en la década de los 80 , la hambruna en el continente africano alertó sobre las limitaciones de las estrategias de lucha contra el hambre, puesto que a pesar de la existencia de alimentos, la desigualdad en la distribución de ingresos y la pobreza acaban constituyéndose en un obstáculo o limitante para el acceso a los alimentos y, por ende, para el cumplimiento de erradicar la pobreza extrema y el hambre.

Durante los años 80 con la expansión del neoliberalismo se apostó a la globalización y, con ello, a la modernización del sector agropecuario, con grandes extensiones de monocultivo y ganadería extensiva, mediante el impulso de la agricultura empresarial, especialmente con fines de exportación; se implementaron políticas y programas que excluyeron a los agricultores familiares, bajo la presión de las compañías transnacionales que monopolizaron el comercio internacional de commodities que posicionaron que lo importante era el acceso a los alimentos en el mercado internacional, además, se desmantelaron las estructuras alimentarias y de asistencia técnica estatal a los pequeños productores.

En 1996 en el marco de la Cumbre Mundial sobre la Alimentación en Roma, se acordó que cada año (hasta el 2015), se debería reducir en 20 millones el número de personas afectadas por el hambre (FAO, 1996). En el 2001 se celebró la Segunda Cumbre Mundial donde se analizaron los progresos en la aplicación del Plan de Acción y se tomaron las decisiones para acelerar el ritmo de la aplicación de medidas orientadas a reducir el número de personas afectadas 
por hambre en el mundo. Sin embargo, los avances logrados desde la cumbre de 1996 en la erradicación del hambre no llegaban ni a la mitad de los objetivos propuestos. La media anual de reducción de personas desnutridas fue sólo de 8 millones. ${ }^{2}$

\section{Soberanía alimentaria y la sociedad civil organizada}

Paralelamente al trabajo de los organismos oficiales, y a partir de foros alternativos y encuentros ciudadanos, la Vía Campesina desarrolló el concepto de soberanía alimentaria que fue llevado al debate público con ocasión de la Cumbre Mundial de la Alimentación de 1996, ofreciendo una alternativa a las políticas neoliberales.

El concepto de soberanía alimentaria plantea el derecho de todos los pueblos y Estados a definir sus propias políticas agrícolas y alimentarias amparadas del concepto soberano y de autonomía con su libre determinación. Se considera la alimentación como un derecho de los pueblos a alimentos sanos y culturalmente adecuados, producidos mediante métodos sustentables. Se da prioridad a la producción y consumo local de alimentos y se proporciona a cada país el derecho de proteger a sus campesinas y campesinos, garantizando el bienestar y la permanencia de la población rural. ${ }^{3}$

En relación a las políticas públicas se considera que para cumplir con el objetivo de Soberanía Alimentaria, estas deben ser adaptadas, territorializadas, diferenciadas, sostenibles; deben impulsar y contribuir al desarrollo de los pueblos y territorios; considerando al territorio como el espacio de vida en el cual se desarrollan todos los vínculos sociales, culturales, económicos, productivos y ambientales (López \& Ramírez, 2012). En este sentido entra en debate el derecho

2 FAO, FIDA y PMA (2015). El estado de la inseguridad alimentaria en el mundo 2015. Cumplimiento de los objetivos internacionales para 2015 en relación con el hambre: balance de los desiguales progresos. Roma, FAO.

3 El concepto fue introducido en 1996 por Vía Campesina en Roma, con motivo de la Cumbre Mundial de la Alimentación de la Organización para la Alimentación y la Agricultura (FAO). 
al territorio rural, parte de la soberanía de un territorio consiste en que los habitantes rurales puedan desarrollar su vida de manera digna con acceso a servicios básicos, salud, educación y tecnologías para proyectarse en el territorio con bienestar colectivo.

Esta mirada ha motivado la emergencia del encuentro y apoyo de varios movimientos sociales rurales y urbanos que buscan la garantía del derecho a alimentos sanos, provenientes de la agricultura familiar, buscando una articulación entre el mundo urbano y rural, y planteando la interdependencia territorial, en la que por ejemplo un territorio rural que provee alimentos, agua, paisaje, semillas, etc. frente a los territorios urbanos con consumidores conscientes. Son ejemplo de estas dinámicas las ferias de productores en espacios urbanos en las cuales se acuerdan precios, fechas de ferias y dinámicas de articulación, igualmente los espacios de tiendas alternativas en las cuales hay vínculos directos con productores especialmente de productos frescos. En la nueva dinámica también existen grupos urbanos que acompañan en la protección de fuentes hídricas y apoyan la sensibilización del consumo responsable del agua.

En esta dinámica, es claro que la soberanía y el desarrollo territorial plantean temas políticos y una disputa de poder entre actores; se presenta un nuevo orden de gobernanza en el que se vuelve a debatir sobre la reforma agraria, el control del territorio, los mercados locales, la biodiversidad, la autonomía, la cooperación, la deuda, la salud, y la capacidad de producir alimentos localmente. Es una disputa en la que se plantea una nueva justicia social que permita el control y acceso justo a la tierra, al agua, y a los recursos genéticos.

\section{Soberanía alimentaria en América Latina y Ecuador}

En los años 80 en América Latina y Ecuador se plantearon medidas para disminuir las importaciones, sin embargo, no estuvieron directamente vinculadas con la generación de incentivos para la producción campesina de alimentos, puesto que bajo la lógica de desarrollo del Neoliberalismo se debilitó la estructura estatal, y la inversión en el sector rural fue marginal. 


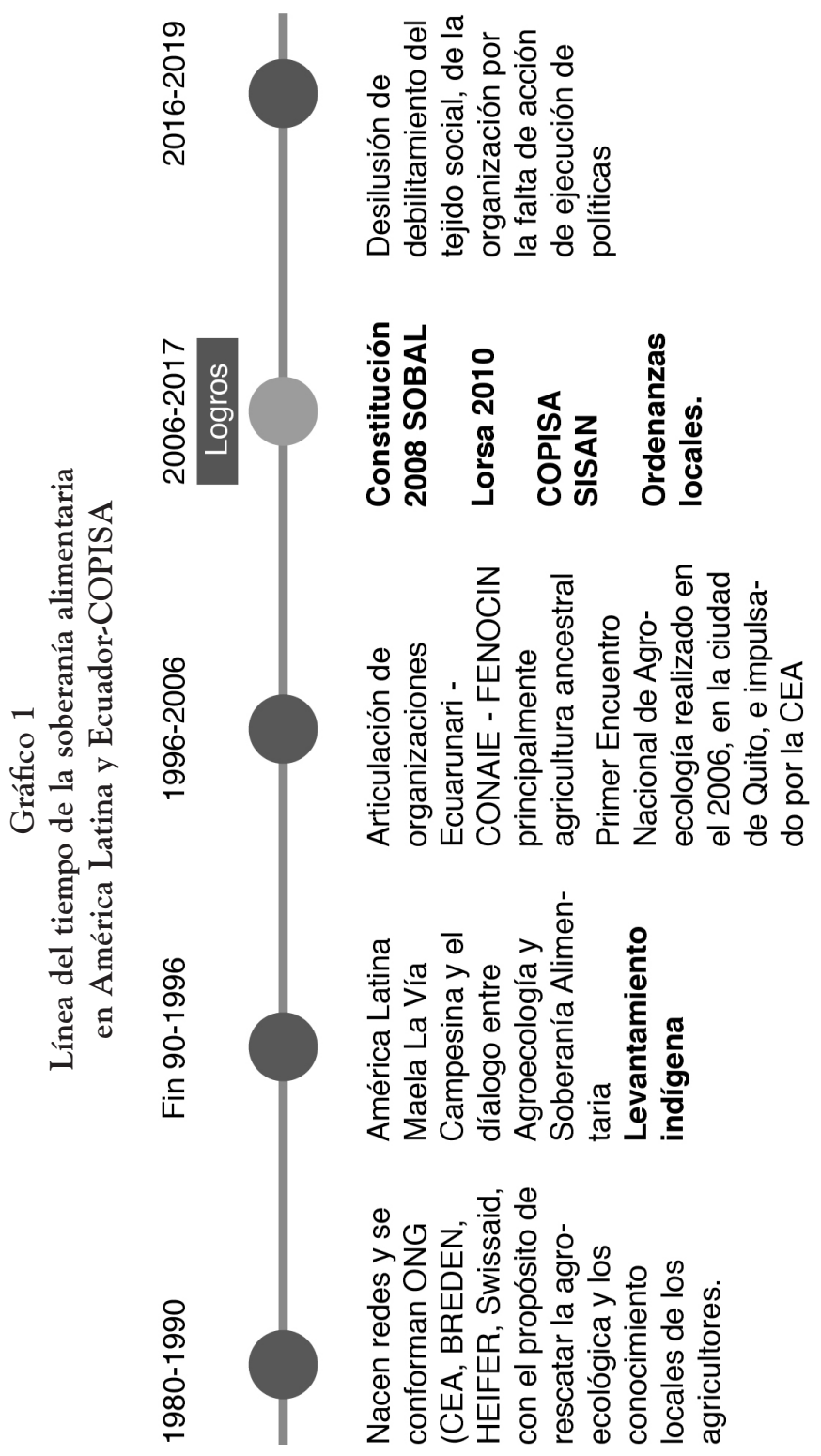


En este contexto, en la región se presentó un debate amplio con una mirada integral sobre el cambio de un modelo de agricultura a otro, vinculando los conceptos de soberanía alimentaria y agroecología, ambos impulsados por ONG y por la sociedad civil para motivar el cambio de las estrategias relacionadas con la revolución verde y la seguridad alimentaria.

En la región se fortalece el impulso de la agroecología, como una visión práctica de que es posible la soberanía alimentaria y la producción de alimentos locales culturalmente adaptados, a través del apoyo de ONG, y el desarrollo y ejecución de proyectos que demuestran las posibilidades de la agroecología. Para el movimiento social se trata de resignificar la lucha campesina (Daza \& Artacker, 2019).

En los años 90 estos conceptos se tornan en discurso y plataforma de algunas organizaciones campesinas que reivindican la producción local y las prácticas ancestrales que aseguran la sostenibilidad. Es necesario citar en los años 90 el levantamiento indígena en Ecuador que da lugar a un nuevo momento de interrelaciones entre los habitantes del mundo urbano y rural, y se constituye la plataforma que en la Constituyente de Montecristi defenderá conceptos centrales como la agroecología y la soberanía alimentaria (ver gráfico 1).

\section{La normativa legal en Ecuador}

En la Constituyente de Montecristi en 2008 se logra posicionar los conceptos de soberanía alimentaria y agroecología impulsados por varias organizaciones campesinas y ONG como base para la trasformación social, y la disputa política entre actores a nivel territorial.

La soberanía alimentaria plasmada en la Constitución del 2008 es un logro de las organizaciones sociales y campesinas, nacionales y regionales, que plantearon este tema como un objetivo estratégico y una obligación del Estado para garantizar que las personas, comunidades, pueblos y nacionalidades alcancen la autosuficiencia de alimentos sanos y culturalmente apropiados de forma permanente. 
La Constitución plantea desde dos ejes, uno desde la garantía de los derechos de los ciudadanos y otro desde los Derechos de la Naturaleza, un total de trece (13) artículos que apuntan al acceso a los medios de producción, al respeto de las prácticas culturales, y al acceso a los alimentos sanos (Ver tabla 1) (Asamblea Constituyente 2008).

\section{Tabla 1}

Resumen de artículos constitucionales con referencia a los derechos ciudadanos y de la naturaleza en Ecuador

\begin{tabular}{|c|c|c|c|}
\hline Derecho & Artículo & Derecho & Artículo \\
\hline \multirow{10}{*}{$\begin{array}{l}\text { Derechos } \\
\text { de los } \\
\text { Ciudadanos }\end{array}$} & $\begin{array}{l}\text { Art. } 13 \\
\text { al acceso seguro } \\
\text { y permanente a } \\
\text { alimentos }\end{array}$ & \multirow{10}{*}{$\begin{array}{l}\text { Derechos } \\
\text { de la } \\
\text { Naturaleza }\end{array}$} & \multirow[t]{2}{*}{$\begin{array}{l}\text { Art. } 322 \\
\text { tecnologías ambientalmen- } \\
\text { te limpias y de energías } \\
\text { alternativas }\end{array}$} \\
\hline & \multirow{2}{*}{$\begin{array}{l}\text { Art. } 71 \\
\text { vivir en un ambiente } \\
\text { sano }\end{array}$} & & \\
\hline & & & \multirow{2}{*}{$\begin{array}{l}\text { Art. } 400 \\
\text { la biodiversidad, cuya ad- } \\
\text { ministración y gestión se } \\
\text { realizará con responsabili- } \\
\text { dad intergeneracional }\end{array}$} \\
\hline & \multirow{3}{*}{$\begin{array}{l}\text { Art. } 281 . \\
\text { Literales } 10-11 \\
13-14 \\
\text { Soberanía } \\
\text { Alimentaria } \\
\text { Garantizar autosufi- } \\
\text { ciencia de alimentos } \\
\text { sanos y cultural- } \\
\text { mente apropiados de } \\
\text { forma permanente. }\end{array}$} & & \\
\hline & & & $\begin{array}{l}\text { Art. } 401 \\
\text { Se declara al Ecuador } \\
\text { libre de cultivos y semi- } \\
\text { llas transgénicas. }\end{array}$ \\
\hline & & & $\begin{array}{l}\text { Art. } 402 \\
\text { Se prohíbe también la }\end{array}$ \\
\hline & \multirow{2}{*}{$\begin{array}{l}\text { Art. } 282 \\
\text { Medios de } \\
\text { producción } \\
\text { prohíbe el latifundio } \\
\text { y la concentración } \\
\text { de la tierra, así como } \\
\text { el acaparamiento } \\
\text { o privatización del } \\
\text { agua y sus fuentes }\end{array}$} & & $\begin{array}{l}\text { apropiación sobre los recur- } \\
\text { sos genéticos que contienen } \\
\text { la diversidad biológica y } \\
\text { la agrobiodiversidad. }\end{array}$ \\
\hline & & & $\begin{array}{l}\text { Art. } 411 \\
\text { Estado garantizará la con- } \\
\text { servación, recuperación } \\
\text { y manejo integral de los } \\
\text { recursos hídricos, cuencas }\end{array}$ \\
\hline & \multirow{2}{*}{$\begin{array}{l}\text { Art. } 402 \\
\text { Se prohíbe toda for- } \\
\text { ma de apropiación } \\
\text { de conocimientos } \\
\text { colectivos, en el ám- } \\
\text { bito de las ciencias, } \\
\text { tecnologías y saberes } \\
\text { ancestrales }\end{array}$} & & $\begin{array}{l}\text { hidrográticas y caudales } \\
\text { ecológicos asociados al ciclo } \\
\text { hidrológico }\end{array}$ \\
\hline & & & $\begin{array}{l}\text { Art. } 409 \\
\text { Prioridad nacional la conser- } \\
\text { vación del suelo, en especial } \\
\text { su capa fértil }\end{array}$ \\
\hline
\end{tabular}


Como consecuencia de este logro inicial en el 2010, nuevamente con un fuerte impulso, movilización y participación social se aprobó la Ley Orgánica de Régimen de Soberanía Alimentaria (LORSA), que se creyó contaba con la base para generar una transformación en el sector rural principalmente vinculada al acceso a la tierra, al agua, así como a las semillas, e incorporaba la participación ciudadana como un elemento clave a través de la creación de la Conferencia Plurinacional e Intercultural de Soberanía Alimentaria (COPISA), misma que debía plantear mecanismos de interrelación Estado-sociedad para la elaboración participativa de leyes y normativas, veedurías, foros de discusión sobre políticas sectoriales en torno a la soberanía alimentaria.

La LORSA plantea garantizar la autosuficiencia e incentivar el consumo de alimentos sanos, nutritivos de origen agroecológico y orgánico, promover prácticas de manejo de biodiversidad y su entorno natural, facilitar la producción y distribución de insumos orgánicos y estimular la producción agroecológica, orgánica y sustentable.

La Ley Orgánica de Régimen de Soberanía Alimentaria LORSA, permitió el desarrollo de una institucionalidad, políticas, programas y proyectos, dirigidos al sector campesino productor de alimentos, sin embargo; los efectos de las inversiones y la implementación de programas y proyectos, no han permitido cumplir con el Art. 1 de esta ley que plantea

Fomentar la producción suficiente y la adecuada conservación, intercambio, transformación, comercialización y consumo de alimentos sanos, nutritivos, preferentemente provenientes de la pequeña, la micro, y mediana producción campesina, de las organizaciones económicas populares y de la pesca artesanal así como de la microempresa y la artesanía; respetando y protegiendo la agrobiodiversidad, los conocimientos y formas de producción tradicionales y ancestrales, bajo los principios de equidad, solidaridad, inclusión, sustentabilidad social y ambiental. 
La Constitución y el Código Orgánico de Organización Territorial, Autonomía y Descentralización (COOTAD) transfirieron competencias a los gobiernos autónomos descentralizados (GAD) provinciales, cantonales y parroquiales que tienen relación con la producción o comercialización. En este sentido una de sus competencias más relevantes es el fomento de las actividades productivas y agropecuarias (Constitución, Art. 263, literales 4), 6), 7) para los GAD provinciales; Art. 267 literal 4) para los GAD parroquiales); para ejercerlas (Art. 135, COOTAD) deben actuar de manera coordinada y compartida, observando las políticas emanadas de las entidades rectoras en materia productiva y agropecuaria, y tomando en cuenta las características y vocaciones productivas territoriales.

Tabla 2

Principales ordenanzas provinciales
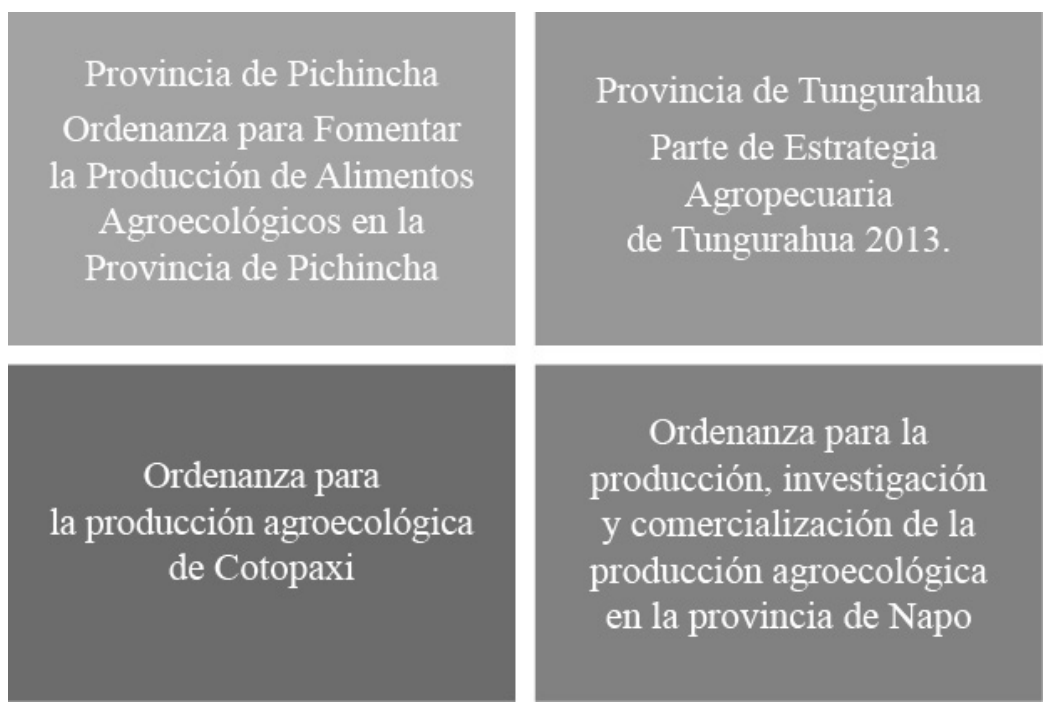

A nivel provincial, paulatinamente y por presión de distintos actores sociales, se han ido desarrollando ordenanzas de impulso a la producción agroecológica como un mecanismo que permite alcanzar la soberanía alimentaria. 
Otras ordenanzas provinciales en proceso:

1. Normativa para impulsar la producción agroecológica con el Gobierno Provincial de Imbabura

2. Ordenanza que promueve la recuperación, uso sustentable y conservación de la agro biodiversidad de la provincia de Chimborazo

3. Ordenanza para impulso de la Soberanía Alimentaria y la pesca artesanal Manabí

4. Ordenanza para impulso de la Soberanía Alimentaria y la pesca artesanal Santa Elena

5. Ordenanza que establece la política pública y el modelo de régimen de seguridad y soberanía alimentaria; y, el desarrollo productivo local en la provincia del Azuay, 2017.

Cabe señalar que el impulso a estas ordenanzas a nivel provincial o local de fomento a la producción agroecológica, generaron movilización local, nuevos liderazgos y la posibilidad de construir territorios agroecológicos y soberanos.

Estas ordenanzas permitieron también plasmar la aplicabilidad del concepto de Desarrollo territorial, y la efectividad de la política pública territorializada y adaptada. Sin embargo, es claro que en esta dinámica la disputa política del poder es más evidente y genera reacciones en el tejido territorial, y las articulaciones entre el espacio urbano y rural se tornan más evidentes, incluso demostrando que el espacio urbano no es solo el espacio de consumo sino de actores consumidores que también están en una disputa por el acceso a alimentos, y que el territorio rural es el espacio que garantiza el agua que se consume en la ciudad, el paisaje, las semillas, el saber y la cultura, que en el espacio urbano se desvanece por la mezcla de identidades diversas. 
Tabla 3

Principales ordenanzas cantonales

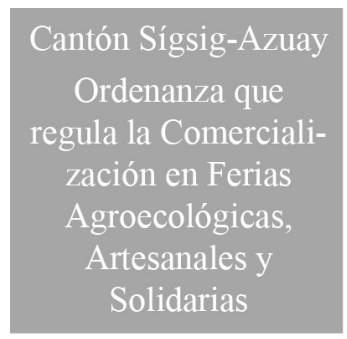

Ordenanza para el fomento y regulación de las Ferias Agroecológicas del cantón Pedro Moncayo
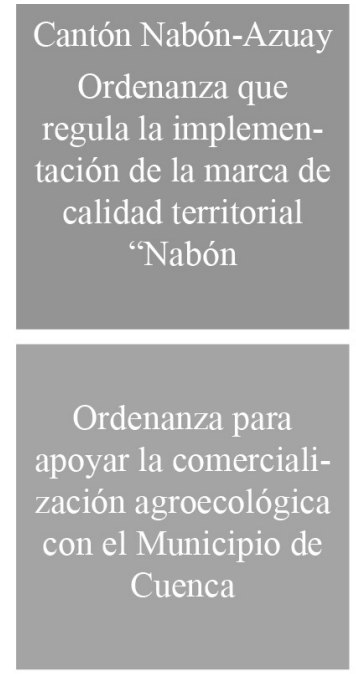

Ordenanza para impulsar la comercialización agroecológica en Gualaceo.

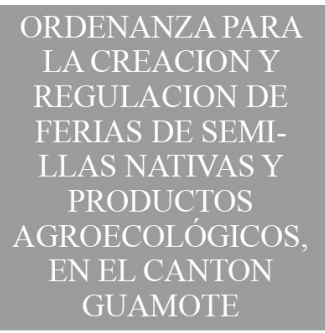

Ordenanza de Fomento a la comercialización de

la producción agroecológica del Cantón Cayambe

\section{Conferencia Plurinacional e Intercultural de Soberanía Alimentaria (COPISA)}

Como consecuencia de la LORSA se crea la Conferencia Plurinacional e Intercultural de Soberanía Alimentaria (COPISA), organismo del poder ciudadano instituido por la Ley Orgánica del Régimen de Soberanía Alimentaria (LORSA), publicado en el Registro Oficial No 583, el 5 de mayo del 2009, y reformado el 27 de diciembre de 2010.

Es clave entender esta estructura como parte del poder ciudadano que implica que todos los ciudadanos que forman parte de una 
nación, para ver cumplidos sus derechos, no sólo deben elegir a sus representantes, sino también controlarlos y desarrollar mecanismos de veeduría; el pueblo debe ejercer su derecho a controlar a sus gobernantes si así lo considera necesario.

La COPISA está conformada por 9 representantes de la sociedad civil, seleccionados y designados por el Consejo de Participación Ciudadana y Control Social (CPCCS), mediante concurso público de merecimientos y oposición, los mismos que deben desarrollar actividades relacionadas con la Soberanía Alimentaria, la Salud y la Nutrición. Los sectores representados son:

- Universidades, escuelas politécnicas y centros de investigación.

- Consumidores.

- Pequeños y medianos productores.

- Pequeños y medianos agricultores.

- Pequeños y medianos ganaderos.

- Pescadores artesanales, recolectores.

- Sector acuícola.

- Campesinos y regantes.

- Indígenas, afroecuatorianos y montuvios, provenientes de las distintas comunas, comunidades, pueblos y nacionalidades.

Visión al 2021, promueve procesos de diálogo, articulación y construcción participativa de propuestas de políticas públicas y veeduría en materia de soberanía alimentaria.

Misión, incide en la construcción, implementación y acompañamiento participativo al cumplimiento de las políticas públicas y del SISAN, a través de un amplio proceso de diálogo, coordinación y articulación, entre la Sociedad Civil y Estado.

Objetivo general, promover la articulación entre la sociedad civil organizada, no organizada y entidades e instancias del sector público, en la construcción, implementación y acompañamiento al cumplimento de las políticas públicas, para alcanzar la SOBA (Soberanía Alimentaria). 
El SISAN es el conjunto articulado de personas, comunas, comunidades, pueblos y nacionalidades, actores sociales, institucionales y estatales involucrados.

\section{Funciones y atribuciones del Sistema de Soberanía Alimentaria y Nutricional (SISAN)}

- Elaborar propuestas de políticas públicas en relación al régimen de la soberanía alimentaria, las que deberán ser puestas en conocimiento del Ministerio Sectorial para su correspondiente aprobación.

- Coordinar entre la sociedad civil y los diversos niveles de gobierno los asuntos relacionados con la soberanía alimentaria, en áreas como: producción, comercialización, distribución, transformación, consumo responsable e influencia en la alimentación y nutrición de personas, comunas, comunidades, pueblos y nacionalidades.

- Promover el cumplimiento en todo el territorio nacional de la Ley Orgánica del Régimen de la Soberanía Alimentaria, a través de sus diversas instancias.

A continuación, un resumen de los logros iniciales de la COPISA:

Tabla 4

Resumen de los logros iniciales de la COPISA

\begin{tabular}{|l|l|}
\hline \multicolumn{1}{|c|}{ COPISA } & \multicolumn{1}{c|}{ SISAN } \\
\hline $\begin{array}{l}\text { Construcción Participativa de las pro- } \\
\text { puestas de leyes conexas a la LORSA. } \\
\text { Leyes presentadas a La Asamblea tres } \\
\text { (3) aprobadas. (agua, tierra, semillas y } \\
\text { agrobiodiversidad). }\end{array}$ & $\begin{array}{l}\text { Articulación diversos actores para re- } \\
\text { flexionar y proponer alternativas para la } \\
\text { fortalecer la Soberanía Alimentaria. }\end{array}$ \\
\hline $\begin{array}{l}\text { Generación de participación y organiza- } \\
\text { ción territorial para construir propuestas. }\end{array}$ & $\begin{array}{l}\text { Apoyo a la construcción de propuestas de } \\
\text { Ordenanzas a nivel Local. }\end{array}$ \\
\hline $\begin{array}{l}\text { Procesos de capacitación ciudadana a } \\
\text { través de escuelas y módulos puntuales. }\end{array}$ & $\begin{array}{l}\text { Apoyo en la estructuración } \\
\text { de organización. } \\
\text { Escuelas Campesinas. }\end{array}$ \\
\hline
\end{tabular}

Fuente: COPISA (Tito Barreno) 
En este sentido es importante señalar que posterior a la Constitución del 2008, hubo la voluntad política de fortalecer el Estado, generando institucionalidad, a nivel central y descentralizado. En los temas agrarios se creó la Autoridad Única del Agua-SENAGUA, y el Ministerio de Agricultura, Ganadería, Acuacultura y Pesca retoma su rol de definidor de políticas públicas y operador territorial, destinando presupuesto para programas y proyectos denominados emblemáticos basados en el plan del Buen Vivir Rural (2013-2017), además, se logra incluir en la estructura del Ministerio de Agricultura y Ganadería, la Subsecretaría de Agricultura Familiar y Campesina, compromiso presidencial Nro. 0093, solicitada por el presidente Lenin Moreno, efectuada el 19 de Julio 2017, en el XII Congreso de la Confederación Nacional de Organizaciones Campesinas, Indígenas y Negras del Ecuador (FENOCIN).

Las políticas planteadas, sin embargo, han tenido pocos recursos y fueron vistas y pensadas desde la centralidad sin articular con los actores locales, las prefecturas y las alcaldías, dejando como consecuencia territorios en los cuales no tuvieron impacto por trabajar en lógica de cadena, favoreciendo directamente algunos productos, principalmente de exportación, pero no a la agricultura familiar campesina.

Con las leyes aprobadas de agua, tierras, semillas y agrobiodiversidad, se buscó garantizar la propiedad sobre los medios de producción como base del discurso de la tierra para quien la trabaja, sin embargo, ya en la práctica las leyes no permiten una verdadera distribución y los mecanismos pensados para el efecto como el Fondo Nacional de Tierras (FONATI), no han aterrizado en mecanismos, recursos, ni institucionalidad que los agilite.

En el año 2011, la Subsecretaría Nacional de Tierras del MAGAP recibió 4 millones de dólares, a diferencia del Programa de las Unidades de Almacenamiento (UNA), que trabaja con maíz y arroz, productos de destino industrial, cuyo presupuesto fue de 96 millones que representó en esa época el 42\% del presupuesto total del Ministerio de Agricultura, Ganadería, Acuacultura y Pesca. 
En relación al crédito, se fortalece el Banco Nacional de Fomento, pero en la puesta en marcha se prioriza el sector agroindustrial, y los servicios de ganadería a gran escala.

Tabla 5

Resumen de las Políticas dentro del Plan Nacional del Buen Vivir 2013 - 2017, la práctica desde el MAG y la perspectiva de COPISA:

\begin{tabular}{|c|c|c|}
\hline Políticas & Lo que se hizo & Situación actual \\
\hline $\begin{array}{l}\text { 1. Impulsar la seguridad y } \\
\text { soberanía alimentarias a } \\
\text { través de un mejor acceso } \\
\text { a alimentos. } \\
\text { 2. Democratizar el acceso a } \\
\text { tierra, agua, semillas, crédito } \\
\text { y otros insumos. } \\
\text { 3. Fomentar la asistencia } \\
\text { técnica, capacitación y } \\
\text { otros procesos de transfe- } \\
\text { rencia de conocimientos y } \\
\text { tecnologías. } \\
\text { 4. Fortalecer la agricultura } \\
\text { familiar campesina y fo- } \\
\text { mentar su encadenamiento } \\
\text { hacia mercados internos } \\
\text { y externos. } \\
\text { 5. Promover el uso de prác- } \\
\text { ticas y conocimientos ances- } \\
\text { trales en la agricultura. } \\
\text { 6. Promover la conser- } \\
\text { vación de suelo y agua, y } \\
\text { prevenir la degradación de } \\
\text { dichos recursos. } \\
\text { 7. Fomentar la producción } \\
\text { y la sustitución de importa- } \\
\text { ciones agrícolas. } \\
\text { 8. Reducir la expansión de la } \\
\text { frontera agrícola. }\end{array}$ & $\begin{array}{l}\text { “Minga Agropecuaria”: Des- } \\
\text { estructuró organizaciones. } \\
\text { Se invierte en: } \\
\text { * Kits de agroquímicos y } \\
\text { semillas certificadas. } \\
\text { La inversión en programas } \\
\text { dirigidos a la Agricultura } \\
\text { Familiar Campesina (AFC) } \\
\text { es marginal. } \\
\text { Los resultados de democra- } \\
\text { tización de acceso agua y } \\
\text { tierra no tienen resultados } \\
\text { de impacto. }\end{array}$ & $\begin{array}{l}\text { 1. Limitada capacidad ope- } \\
\text { rativa de las instituciones } \\
\text { 2. Rotación frecuente de los } \\
\text { equipos } \\
\text { 3. Legislación contradictoria } \\
\text { a nivel local y secundario } \\
\text { 4.Disminución de recursos } \\
\text { de inversión del Estado } \\
\text { 5. Desaceleración de la eco- } \\
\text { nomía en } 2017 \text { y } 2018 \\
\text { 6. Alianzas con el agro-ne- } \\
\text { gocio, con aprobación de } \\
\text { acuerdos ministeriales como } \\
\text { el del } 11 \text { de enero que decla- } \\
\text { ra el día del pollo, con Co- } \\
\text { nave, AFABA, y Aprobal. }{ }^{40}\end{array}$ \\
\hline
\end{tabular}

Fuente: Plan Nacional del Buen Vivir 2013-2017.

5 Corporación Nacional de Avicultores del Ecuador (CONAVE), Asociación Ecuatoriana de Fabricantes de Alimentos Balanceados para Animales (AFABA) y la Asociación de Productores de Alimentos Balanceado (APROBAL). 


\section{Situación actual al 2019}

Durante el periodo 2017-2019, se ha visto un nuevo momento de acceso al poder de la clase agroexportadora, empresarial y de la Banca, quienes han logrado concentrar poder en el Gobierno, en distintos niveles, generándose un nuevo momento de aplicación de políticas neoliberales, un nuevo debilitamiento del Estado y disminución de la inversión social.

Lo dicho se constata en la disminución de funcionarios y técnicos, especialmente a nivel desconcentrado, y la disminución de los recursos de inversión que limitan acción en los territorios.

Se ha planteado que las carteras de Estado sean únicamente diseñadoras de la política pública, dejando la operación a los Gobiernos Intermedios y locales, que sin embargo nunca han recibido recursos efectivos por la competencia de Fomento Productivo.

Esta situación deja un nuevo momento en el que se necesita un nuevo proceso de organización social, urbana y rural que permita la defensa de los diversos sectores especialmente de los derechos ya adquiridos.

\section{Conclusiones}

La soberanía alimentaria en Ecuador los últimos diez años ha tenido altos y bajos, un alto es haber posicionado el concepto en la Constitución como un derecho humano vinculado al acceso al alimento; es elemento relevante también haber logrado la ley de Soberanía Alimentaria LORSA, en la cual además se crea una institucionalidad basada en la participación ciudadana para proponer, impulsar y desarrollar propuestas de ley para el fortalecimiento de la SOBAL.

Se logró aprobar la ley de tierra, agua y semillas, que, si bien no tiene todos los elementos planteados por las organizaciones campesinas, permitió ver algunos elementos desde ópticas más modernas. 
La creación de la institucionalidad ha permitido generar incidencia particularmente a nivel local para activar el Sistema de Soberanía Alimentaria y lograr articulaciones de programas y proyectos.

Se motivó el diseño de programas y proyectos dirigidos a la Agricultura familiar campesina, sin embargo, estos en muchos casos son marginales y no responden a las necesidades campesinas, como, por ejemplo, el Kit de insumos que termina favoreciendo principalmente a las empresas de agroquímicos. El MAG calificó a trece empresas proveedoras de paquetes tecnológicos; las empresas calificadas son Agripac, Crystal Chemical, Del Monte, Ecuaquímica, El Agro, Farmagro, Fertisa, Interoc, Pronaca, Solagro y la empresa pública Unidad Nacional de Almacenamiento (UNA E.P.); y son las únicas que tendrán acceso a la plataforma con el registro de agricultores, con derecho al subsidio del MAG.

Se dio prioridad a la lógica de cadena y a los productos con potencial de exportación sin considerar la importancia de los alimentos para el consumo local.

Desde las organizaciones campesinas se ha mantenido el interés por solicitar inversiones y acciones al Estado para la SOBAL, sin embargo, estas también terminan siendo relegadas y no existe por parte de las organizaciones agendas concesionadas relacionadas con los temas agrarios.

\section{Bibliografía}

Asamblea Constituyente (2008). Constitución de la República del Ecuador. Daza, E., \& Artacker, T. (2019). El sentido agroecológico: Por una dimensión política de la agroecología. Vol. 10, Cuaderno de reflexión. Quito: IEE, OCARU.

FAO (1996). Cumbre Mundial sobre la Alimentación. Roma.

República del Ecuador (2009). Ley Orgánica del Régimen de la Soberanía Alimentaria. En Registro Oficial Suplemento 583, 5 de mayo de 2009. Heifer-Ecuador. La Agroecología está presente. Recuperado de: https://bit. ly/2WzEQxs 
104

López, L., \& Ramírez, B. (2012). Pensar el espacio: región, paisaje, territorio $y$ lugar en las ciencias sociales. Universidad Autónoma Metropolitana Xochimilco.

Ministerio de Agricultura (2016). La política agropecuaria ecuatoriana: Hacia el desarrollo territorial sostenible 2015-2015. Quito: MAG.

ONU (1974). Declaración Universal sobre la erradicación del hambre y la malnutrición. (Ed. Asamblea General de las Naciones Unidas).

Voluntariat Solidari (2016). Historia de la soberanía alimentaria. Vols ONG. Recuperado de: https://bit.ly/2HlGGsY 